\title{
Transcriptional cosuppression of yeast Ty1 retrotransposons
}

\author{
Yi Wei Jiang ${ }^{1}$ \\ Department of Medical Biochemistry and Genetics, Texas A\&M University System Health Science Center, \\ College Station, Texas 77843-1114, USA
}

\begin{abstract}
Cosuppression, the silencing of dispersed homologous genes triggered by high copy number, may have evolved in eukaryotic organisms to control molecular parasites such as viruses and transposons. Ty1 retrotransposons are dispersed gene repeats in Saccharomyces cerevisiae, where no cosuppression has been previously observed. Ty1 elements are seemingly expressed undeterred to a level as high as $10 \%$ of total mRNA. Using Ty1-URA3 reporters and negative selection with 5 -fluoroorotic acid, it is shown that Ty1 genes can undergo transcriptional cosuppression that is independent of DNA methylation and polycomb-mediated repression. Expression of Ty1-related genes was shown to be in one of two states, the coexpressed state with all Ty1-related genes transcribed or the cosuppressed state with all Ty1-related genes shut off, without uncoordinated or mosaic expression in any individual cell. Rapid switches between the two states were observed. A high copy number of Ty1 elements was shown to be required for the initiation of Ty1 homology-dependent gene silencing, implying that Ty1 gene expression is under negative feedback control. Ty1 transcriptional repressors facilitated the onset of $T y 1$ cosuppression, and the native $T y 1$ promoters were required for $T y 1$ cosuppression, indicating that $T y 1$ cosuppression occurs at the transcriptional level.
\end{abstract}

[Key Words: Cosuppression; Ty1; transcription; retrotransposition; DNA methylation]

Received June 28, 2001; revised version accepted December 14, 2001.

Cosuppression, which has been defined as high gene copy number-triggered homology-dependent gene silencing (Jorgensen 1995), may have evolved in eukaryotes to control invasive molecular parasites such as viruses and transposons (Wolffe and Matzke 1999). Cosuppression first came to attention when attempts to boost gene expression in transgenic plants resulted in cosilencing of both the transgenes and the homologous endogenous genes. Cosuppression can be distinguished from other forms of gene silencing by the high target gene copy number-dependent initiation and homology-dependent spreading. Cosuppression has been observed in many organisms, and it appears in two forms, posttranscriptional gene silencing (PTGS, also known as RNA interference or RNAi) and transcriptional gene silencing (TGS). In PTGS, homologous genes are silenced by homologous RNA duplex-mediated mRNA degradation (Grant 1999; Hamilton and Baulcombe 1999; Bass 2000; Hammond et al. 2000; Zamore et al. 2000). The mechanisms of TGS are poorly understood. For example, a white promoterAdh gene fusion construct was integrated into the Drosophila genome, and it was found that an increased copy number of the fusion gene resulted not only in reduced expression of the fusion genes, but also in reduced ex-

${ }^{1}$ E-MAIL ywjiang@medicine.tamu.edu; FAX (979) 847-9481. Article and publication are at http://www.genesdev.org/cgi/doi/10.1101/ gad.923502. pression of the endogenous Adh gene (Pal-Bhadra et al. 1997). This cosuppression is sensitive to the dosage of Polycomb-group genes, and the transcriptionally repressive Polycomb proteins are found associated with the cosuppressed fusion genes. In plants and Neurospora, DNA methylation is frequently detected at repetitive genes undergoing TGS (Assaad et al. 1993; Rossignol and Faugeron 1994). Although it is not clear whether the association of Polycomb proteins or DNA methylation is the cause or the consequence of TGS, the role of chromatin structure has been the focus of investigation (Vaucheret and Fagard 2001). However, neither DNA methylation nor Polycomb homologs are present in Saccharomyces cerevisiae, and thus different mechanisms would be required for any observed cosuppression in budding yeast. It has been suggested that PTGS and TGS may function in synergy (Ingelbrecht et al. 1994; Wassenegger et al. 1994; Al-Kaff et al. 1998; Jones et al. 1999). In plants, an RNA duplex containing promoter sequences can trigger TGS accompanied by de novo methylation of the promoter (Mette et al. 2000), implying a mechanistic connection between TGS and PTGS.

Ty1 elements in S. cerevisiae are retrotransposons. The coding region of Ty1 is flanked by two 340-bp-long terminal repeats (LTRs, or $\delta$ elements) that function as the transcriptional promoter and terminator, respectively. The coding region consists of two overlapping open reading frames: TYA1 (GAG), encoding a structural 
capsid protein (CA); and TYB1 (POL), encoding protease $(\mathrm{PR})$, integrase (IN), and reverse transcriptase (RT). Replication or transposition of Ty1 requires the following steps. RNA polymerase II transcribes Ty1 elements from LTR to LTR, and the RNA is polyadenylated and transported into the cytoplasm. Ty $A$ and Ty $A-T y B$ are translated, and the production of TyA-TyB involves a programmed translational frame shift at a frequency of $3 \%$ (Belcourt and Farabaugh 1990). TyA and TyA-TyB associate with Ty1 mRNA to form virus-like particles (VLPs), wherein TyA is processed into CA and TyA-TyB is processed into CA, PR, IN, and RT. Ty1 protein processing is catalyzed by PR and is essential for transposition (Youngren et al. 1988; Merkulov et al. 1996, 2001). Reverse transcription occurs in the VLP, using tRNA ${ }_{i}{ }^{\text {Met }}$ as a primer (Eichinger and Boeke 1988; Chapman et al. 1992), and the resultant double-stranded Ty1 cDNA is then transported into the nucleus (of the same cell), where either nonhomologous integration catalyzed by IN or homologous recombination with a chromosomal Ty1 occurs.

The transcription of Ty1 elements is under the control of both mating type and the invasive/filamentous growth MAP-kinase pathway. Mating-type control refers to the higher level of Ty1 expression seen in haploids compared to diploids, and the a1/ $\alpha 2$ heterodimeric repressor, which is only present in diploid cells, is responsible for this regulation. Binding sites for the a $1 / \alpha 2$ repressor have been identified in the region of Ty1 nucleotides 815-927 adjacent to the Mcm 1 binding sites (Errede et al. 1987). The invasive/filamentous growth MAP-kinase pathway is activated by nitrogen starvation in diploid cells and by an unknown environmental element in haploid cells, and activity of this signal transduction cascade requires the Ste11, Ste7, and Kss1 kinases. Activation of this pathway results in activation of the Ste12 and Tec1 transcription factors. The Ty1 regulatory region of nucleotides 384-433 contains binding sites for the Ste12 and Tec1 DNA-binding factors (Company et al. 1988; Baur et al. 1997; Madhani and Fink 1997). The level of Ty1 mRNA is about 10-fold lower in wild-type diploid cells compared with haploids (Elder et al. 1981), and similar decreases are seen in ste7, ste11, ste12, and tec1 haploid mutants compared with wild-type haploids (Dubois et al. 1982; Laloux et al. 1990). Additionally, TYA1-lacZ reporters are activated by a constitutive MAPKK kinase Ste11-4 or by nitrogen starvation (Morillon et al. 2000). Ty1 transcription is also activated by DNA-damaging agents in an RAD9-dependent but DUN1-independent fashion (Rolfe et al. 1986; Bradshaw and McEntee 1989; Staleva and Venkov 2001).

Most $S$. cerevisiae strains have about 30 copies of the Ty1 element dispersed throughout the genome, and Ty1 mRNA expression can be as high as $10 \%$ of total mRNA. Cosuppression has never been observed previously for Ty1 elements, although the repeated, dispersed nature of Ty1 elements makes them prime candidates for cosuppression. We report here the detection of abolished expression of Ty1-related genes using Ty1-URA3 reporters plus 5-fluoroortic acid (5-FOA) counterselection. Expres- sion of the entire family of Ty1-related genes was shown to be in one of two states, either all genes expressed or all genes not expressed, without uncoordinated or mosaic expression in any individual cell. Rapid switches between the two states were observed. Investigations in a strain lacking any endogenous Ty1 elements showed that abolished expression of a Ty1-URA3 reporter could only be detected in the presence of a high-copy plasmid carrying the Ty1 element, and this requirement for high Ty1 copy number established this phenomenon as cosuppression. Ty1 transcriptional repressors facilitated the onset of Ty1 cosuppression, and the native Ty1 promoter was required for Ty1 cosuppression, indicating that Ty1 cosuppression occurs at the transcriptional level. The transcription of Ty1 elements in a cell appeared under striking digital control with Ty1 transcriptional repressors enhancing the frequency of Ty1 cosuppression rather than reducing the amplitude of Ty1 transcription, which contradicts the conventional wisdom of Ty1 transcriptional factors regulating the transcriptional amplitude of Ty1 elements.

\section{Results \\ Off-regulation of Ty1-URA3 reporters}

In-frame Ty1-URA3 fusions (driven by the Ty1 promoter) were constructed as reporters for the detection of potential Ty1 cosuppression. URA3 was chosen as the key component for the reporters to take advantage of the fact that both positive and negative selection schemes are available for selecting cells that either do or do not express Ura3 (Boeke et al. 1987). Cells expressing Ura3 can grow without uracil. Because cells expressing Ura3 convert 5-fluoroortic acid (5-FOA) to a toxic compound, only cells lacking the Ura3 enzyme can grow on media containing 5-FOA. A bacterial Tn3 minitransposon, Tn3URA3OT, carrying the URA3 ORF plus a transcriptional terminator, was randomly inserted into a cloned Ty1 element ( $p H S S 6:$ Ty1) via in vitro transposition in Escherichia coli (Fig. 1; Seifert et al. 1986; Burns et al. 1994). The resultant Ty1-URA3 fusions were excised by NotI restriction digestion and introduced into a ura3-1 yeast strain (W303A) via homologous recombination with chromosomal Ty1 elements, and strains carrying in-frame Ty1-URA3 fusions were selected on SC-Ura plates. The $\mathrm{Ura}^{+}$transformants were first purified on nonselective YEPD plates, and then tested for growth on $\mathrm{SC}+5$-FOA. 5-FOA survivors were retested for growth on SC-Ura to rule out the possibility that the 5-FOA survivors had suffered a mutation in the Ty1-URA3 gene.

If there is cosuppression of the Ty1 genes, the partially homologous Ty1-URA3 fusion gene may be turned off or off-regulated in cells undergoing Ty1 cosuppression. Cells with the Ty1-URA3 reporter could be 5-FOA-resistant because expression of the Ty1-URA3 reporter was abolished by cosuppression. Many such $\underline{\mathrm{Ura}}^{+}$and 5 -FOA ${ }^{\mathrm{r}}$ (Ufo) strains with different TYA1- $\overline{U R} A 3$ inframe fusions at various (if not all) Ty1 loci were, indeed, 


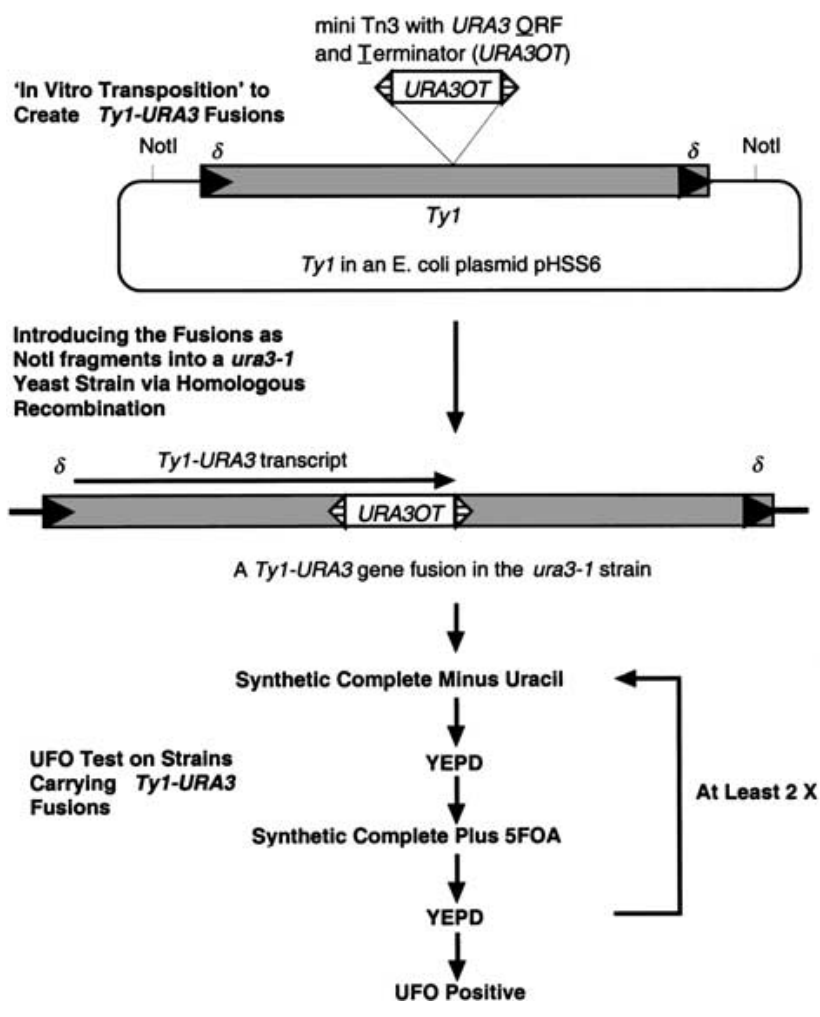

Figure 1. The Ufo scheme to detect Ty1 cosuppression.

obtained. The phenotype of these Ufo strains was reversible, as they were able to survive repeated sequential opposing $\mathrm{Ura}^{+}$and $5-\mathrm{FOA}^{\mathrm{r}}$ selections. The Ufo phenotypes of two Ty1-URA3 strains (Y32 and Y33, carrying reporters Ty1-URA3-32 and Ty1-URA3-33, respectively) are illustrated in Figure 2A. The strains formed colonies on SC-Ura and SC + 5-FOA after $3 \mathrm{~d}$ of incubation at $30^{\circ} \mathrm{C}$. Quantitative titration/plating experiments revealed that only fractions of $\mathrm{Y} 33$ cells from a colony grown on nonselective SC medium formed colonies on SC-Ura $(64 \% \pm 13 \%)$ and SC +5 -FOA $(16 \% \pm 3 \%)$ plates. Microscopic examinations confirmed that a significant fraction of the cells plated on selective media failed to divide (Table 1, lines 2 and 3 ). The failure of $\sim 10 \%$ of the plated cells to divide on SC-Ura unequivocally pointed to the existence of an intrinsic population of cells that do not express Ty1-URA3-33. This result ruled out that potential leakiness of 5-FOA selection allowed $\mathrm{Ura}^{+}$cells to form colonies on 5-FOA or that 5-FOA induced the off-regulation of Ty1-URA3-33. Experiments examining plating efficiencies of strain Y32, with a different Ty1$U R A 3$ reporter integrated at a different chromosomal location gave similar results (data not shown). It should be noted that the Y33 5-FOA ${ }^{\mathrm{r}}$ colony formation efficiency of $16 \%$ underreports the fraction $(64 \%)$ of Y33 cells undergoing transient Ty1 cosuppression (see below).

Southern hybridization analysis showed that Y32 and Y33 each contained a single URA3 gene fusion (Fig. 3A, bottom). Ty1-URA3-32 was cloned and sequenced, and found to be an insertion of URA3OT at nt +635 of yGRW Ty1-1. Ty1-URA3-33 was cloned and sequenced, and found to be an insertion of URA3OT at nt +902 of a Ty1 element unique to W303. When Y33 (MAT 2 Ty1-URA333 ura3-1) was backcrossed to W303B (MATa ura3-1), two $\mathrm{Ura}^{+}$and two $\mathrm{Ura}^{-}$segregants were obtained for each tetrad, confirming a single in-frame Ty1-URA3 in Y33. All $\mathrm{Ura}^{+}$segregants were Mat $\alpha$, suggesting Ty1-URA333 is closely linked to the MAT locus. All $\mathrm{Ura}^{+}$segregants were also capable of growth on 5-FOA /conferring the Ufo phenotype), showing that the Ufo phenotype segregated as a single Mendelian trait and that Ty1-URA333 was sufficient for the Ufo phenotype. Y33, as either a $\mathrm{Ura}^{+}$or $5-\mathrm{FOA}^{\mathrm{r}}$ population, was backcrossed to W303B, and in both cases the Ufo phenotype appeared in half of the segregants. This indicates that the phenotype is not stable through meiosis and that there is no detectable genetic difference between the two phenotypic populations.

To address whether a Ty1-URA3 reporter must be chromosomally located to be off-regulated, plasmid D806 with the Ty1-URA3-33 on a YCp[LEU2] vector was constructed. W303A carrying D806 displayed the Ufo phenotype on SC-Leu-Ura and SC-Leu + 5-FOA media (Fig. 2B), indicating that cosuppression could block expression of the reporter present on a plasmid. However, the expression of an independently expressed URA3 embedded in the Ty1 element at the same position in either orientation (on D1261 and D1262) could not be blocked by cosuppression, indicating that an inframe Ty1-URA3 fusion is required for the Ufo phenotype. Similar results were obtained in an S288C strain, eliminating the possibility that the cosuppression is specific to the W303 strain background.

Although a remote possibility, it is conceivable that the URA3 sequence itself plays a role in the decreased expression of the Ty1-URA3 fusion. To test this possibility, a strain with a Ty1-TRP1 in-frame fusion gene was constructed and tested for growth on a medium with 5-fluoroanthranilic acid (FAA), which kills TRP1+ cells (Toyn et al. 2000). The strain was able to grow on the FAA medium (Fig. 2C), indicating that cosuppression can block the expression of the Ty1-TRP1 reporter. This shows that off-regulation of a Ty1-related gene does not depend on the URA3 sequence.

\section{Concerted off-regulation of Ty1-related genes}

Although the growth of the Ty1-URA3 strains on media containing 5-FOA indicates the absence of Ura3 activity, these experiments do not address whether the growth resulted from reduced levels of Ty1-URA3 mRNA or not. Northern assays were performed to determine the mRNA levels of Ty1-URA3-33 and ACT1 (as a control; Fig. 3A, right). The results show that Ty1-URA3-33 mRNA is expressed when Y33 cells are grown in the absence of uracil (SC-Ura), but is absent from Y33 cells grown on medium containing 5-FOA (SC + 5-FOA).

Because one hallmark of cosuppression is homologydependent gene silencing, it is critical to determine whether genes sharing homology with Ty1-URA3-33 are off-regulated in concert with Ty1-URA3-33. Northern 


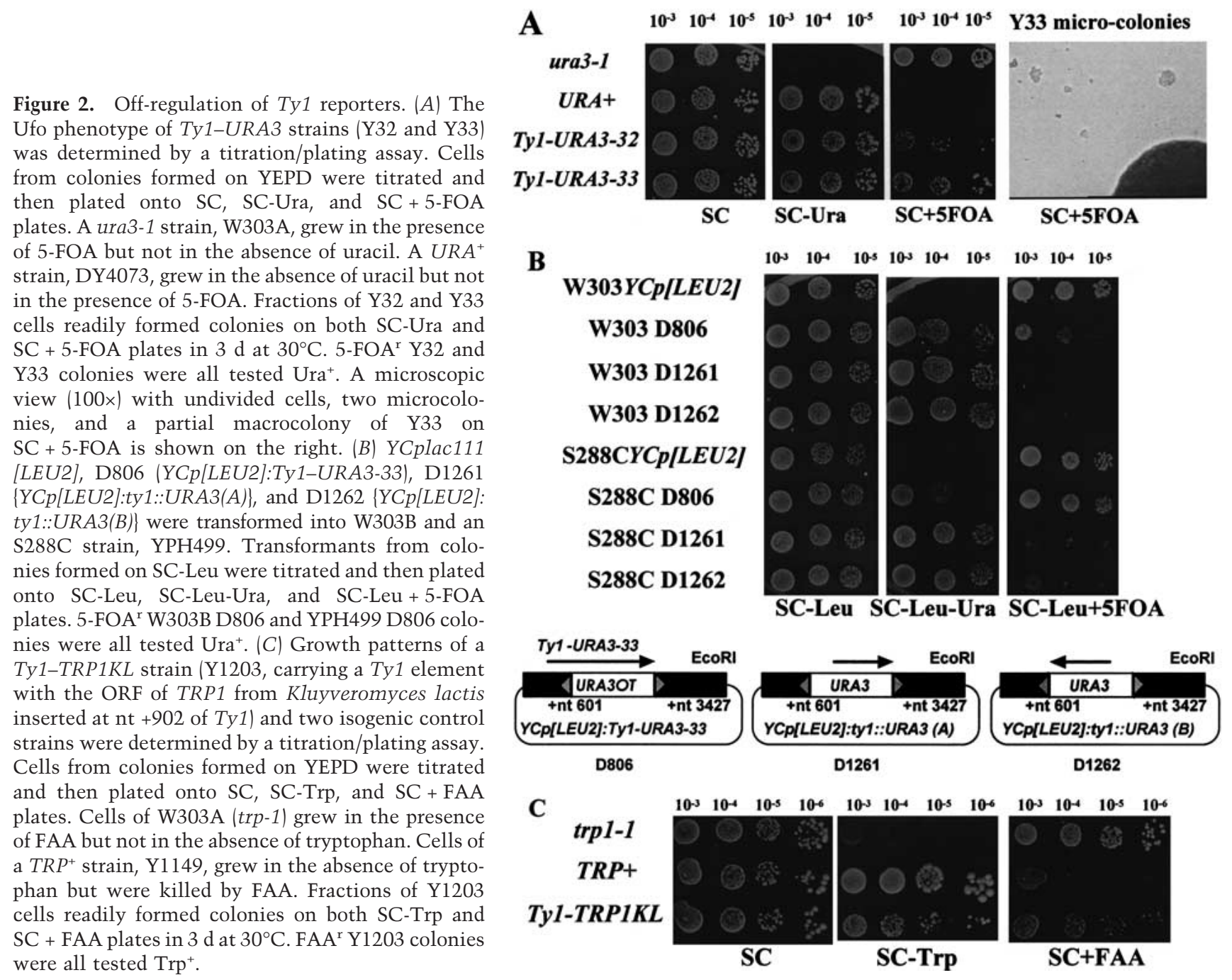

assays were performed to determine the mRNA levels of genes sharing homology with Ty1-URA3-33, the endogenous Ty1 genes, and the native ura3-1 in the same cells (Fig. 3A, right). The results show that Ty1-URA3-33 and Ty1 mRNAs are coregulated. They were expressed in Y33 cells grown in the absence of uracil (SC-Ura), but were absent in Y33 cells grown in the presence of 5-FOA (SC + 5-FOA). Genes unrelated to Ty1, such as ura3-1 and ACT1, were expressed normally in Y33 cells grown in SC + 5-FOA. A modest threefold reduction of ura3-1 mRNA was observed in Y33 cells grown in SC + 5-FOA, and it was likely to be the result of Pprl-mediated metabolic repression by uracil in the medium (Denis-Duphil 1989). The abolished expression of Ty1-related genes was also detected in ppr1 cells in which ura3-1 mRNA did not depend on the concentration of uracil (data not shown). A Southern assay of genomic DNA showed that the Ty1-URA3-33 reporter remains intact in the Y33 cells grown in the $\mathrm{SC}+5$-FOA medium, eliminating the possibility that loss of the Ty1-URA3-33 reporter causes the absence of Ty1-URA3-33 mRNA. Except for a yet to be understood fuzziness of Ty1-URA3-32 Northern signals, the same results were obtained with Y32 (Fig. 3A, left). These results show that Ty1 homology is required for the cosuppression.

The Ty1 homology-dependence was confirmed in two control experiments that showed the specificity of the Ty1-URA3 plus 5-FOA reporting method. Cells with the ura3-1 allele can grow on 5-FOA, and cells with URA3 at a telomeric location can grow on 5-FOA because of telomeric gene silencing (Gottschling et al. 1990). Growth of these cells on 5-FOA did not result in loss of Ty1 expression (Fig. 3B), showing that growth on 5-FOA per se does not cause loss of Ty1 mRNA.

If the expression of Ty1-related genes in a cell is not coordinated, loss of one Ty1-related gene's expression will always be associated with expression of some other Ty1-related genes in the cell to result in a mosaic pattern of Ty1 expression. In other words, mosaic expression of Ty1 elements in a cell is not compatible with the coordinated off-regulation of Ty1-related genes observed here, and the above results show that Ty1 elements are either all expressed or all turned off with no mosaic expression of Ty1 elements in the same cell. Growth of Ty1-URA3 cells in SC + 5-FOA selects those cells not expressing Ty1 elements, growth of Ty1-URA3 cells in 
Table 1. Microscopic plating efficiencies

\begin{tabular}{|c|c|c|c|c|}
\hline & Culture history & $\begin{array}{c}\mathrm{Y} 33 \\
(\operatorname{Ty} 1-U R A 3)\end{array}$ & $\begin{array}{l}\text { W303A } \\
\text { (ura3-1) }\end{array}$ & $\begin{array}{l}\text { DY4073 } \\
(U R A+)\end{array}$ \\
\hline 1 & From $\mathrm{SC}$ to $\mathrm{SC}$ & $(98 \pm 1) \%$ & $(98 \pm 1) \%$ & $(99 \pm 1) \%$ \\
\hline 2 & From SC to SC-Ura & $(90 \pm 1) \%$ & $(0 \pm 0) \%$ & $(98 \pm 1) \%$ \\
\hline 3 & $\begin{array}{l}\text { From SC to SC } \\
\quad+5 \text {-FOA }\end{array}$ & $(22 \pm 2) \%$ & $(98 \pm 1) \%$ & $(0 \pm 0) \%$ \\
\hline 4 & From SC-Ura to SC & $(98 \pm 1) \%$ & n.d. & $(98 \pm 1) \%$ \\
\hline 5 & $\begin{array}{l}\text { From SC-Ura to } \\
\text { SC-Ura }\end{array}$ & $(93 \pm 1) \%$ & n.d. & $(98 \pm 1) \%$ \\
\hline 6 & $\begin{array}{c}\text { From SC-Ura to } \\
\text { SC }+5 \text {-FOA }\end{array}$ & $(11 \pm 1) \%$ & n.d. & $(0 \pm 0) \%$ \\
\hline 7 & $\begin{array}{l}\text { From } \mathrm{SC}+5-\mathrm{FOA} \\
\quad \text { to } \mathrm{SC}\end{array}$ & $(23 \pm 1) \%$ & $(99 \pm 1) \%$ & n.d. \\
\hline 8 & $\begin{array}{l}\text { From } \mathrm{SC}+5 \text {-FOA } \\
\quad \text { to } \mathrm{SC} \text {-Ura }\end{array}$ & $(17 \pm 2) \%$ & $(0 \pm 0) \%$ & n.d. \\
\hline 9 & $\begin{array}{c}\text { From } \mathrm{SC}+5-\mathrm{FOA} \\
\text { to } \mathrm{SC}+5-\mathrm{FOA}\end{array}$ & $(22 \pm 1) \%$ & $(98 \pm 2) \%$ & n.d. \\
\hline
\end{tabular}

Cells from a colony formed on a medium were plated onto the same medium or a different one. The plated cells were incubated at $30^{\circ} \mathrm{C}$ overnight and then observed under a light microscope. Microscopic plating efficiency was calculated as the fraction of cells divided at least once on a new medium. The presented efficiencies were averaged from four experiments.

SC-Ura enriches those cells expressing Ty1 elements and growth of Ty1-URA3 cells in SC or YEPD results in a mixture of the two populations.

Another hallmark of cosuppression is that a high copy number of the target gene is required to reduce gene expression (Jorgensen 1995). To examine the role of Ty1 copy number, a Ty 0 strain that completely lacks Ty1 and Ty2 sequences was used (Wilke and Adams 1992). A Ty0 strain was transformed with the Ty1-URA3-33 reporter and either a single-copy centromere plasmid with a Ty1 element (YCp[LYS2]:Ty1) or a multicopy plasmid with a Ty1 element (YEp[LYS2]:Ty1), and the strains were assayed for the ability to grow on 5-FOA (Fig. 4). The results clearly show that expression of the Ty1-URA3-33 reporter can be turned off by the YEp:Ty1 high-copy plasmids but not by the YCp:Ty1 single-copy plasmid. This result shows that high copy number is required for the abolished expression of the Ty1-URA3-33 reporter and qualifies the coordinated off-regulation of Ty1-related genes as bona fide cosuppression. If an epigenetic factor unrelated to Ty1 blocks the expression of Ty1 elements to cause Ty1 cosuppression, it is difficult to imagine that high Ty1 copy number is required for Ty 1 cosuppression. Therefore, the requirement of high Ty1 copy number rules out the involvement of such a Ty1-independent epigenetic factor and points to interactions among Ty1 elements as the key in Ty1 cosuppression. If a Ty1 gene product mediates the interactions among Ty1 elements to initiate Ty1 cosuppression, it would imply negative feedback control of Ty1 gene expression.

\section{A key role of the native Tyl promoters in Tyl cosuppression}

Given that the cosuppression-sensitive Ty1-URA3 reporters are driven by $T y 1$ promoters, it is important to
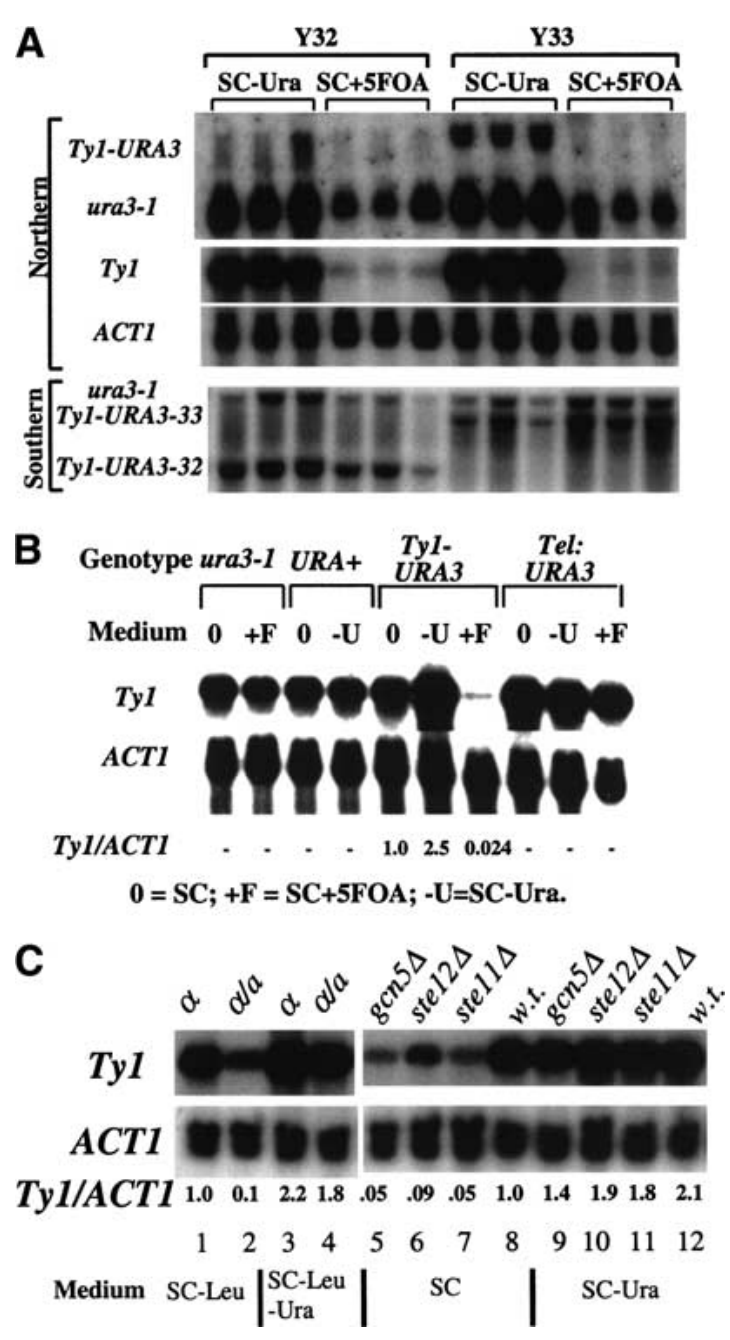

Figure 3. Northern assays. (A) Coordinated off-regulation of Ty1-related genes. Y32 and Y33 were grown in SC-Ura and SC + 5-FOA to the mid-log phase (all in triplicates). Total yeast RNA and genomic DNA were extracted from the cells of each culture, and subjected to Northern and Southern analyses, respectively. The Northern blot was probed with a ${ }^{32} \mathrm{P}$-labeled $1.1-\mathrm{kb}$ HindIII DNA fragment of URA3, a ${ }^{32} \mathrm{P}-$ labeled $1.3-\mathrm{kb}$ SalI-KpnI DNA fragment of TYB1, and a ${ }^{32} \mathrm{P}-$ labeled $1.5-\mathrm{kb}$ $B a m H-H i n d I I I$ DNA fragment of ACT1. No low-molecularweight Ty1 signals were detected after an extended exposure (data not shown). The genomic DNA samples were digested with EcoRI, resolved on a $0.8 \%$ TAE agarose gel, and blotted onto a nitrocellulose membrane. The Southern blot was probed with the same URA3 probe. The signal-containing region of an autoradiograph is shown here with the signals of ura3-1 ( 12 $\mathrm{kb})$, Ty1-URA3-33 ( 11 kb), and Ty1-URA3-32 ( 6 kb) indicated. $(B)$ 5-FOA treatment and the off-regulation of Ty1 elements. W303A (ura3-1), DY4073 (URA3), Y33 (Ty1-URA3), and UCC16 (Tel:URA3) were grown in liquid media as indicated. Total RNA was extracted from the cells and subjected to Northern analysis as described above. (C) Ty1 mRNA levels in mutant cells not undergoing Ty1 cosuppression. Isogenic MATa Ty1URA3-33 strains Y33 (wild-type; lanes 8,12), Y443 (gcn5 4 ; lanes 5,9), Y442 (ste12s; lanes 6,10), Y461 (ste11s; lanes 7,11), Y33 with YCp50-LEU2 (lanes 1,3), and Y33 with YCp50LEU2:MATa (lanes 2,4) were grown in liquid media as indicated; total RNA was extracted and subjected to Northern analysis as described above. 
Figure 4. Ty1 copy number-dependent off-regulation of Ty1-URA3-33. Y1144, a Ty0 strain with YCp[LEU2]Ty1-URA333, was transformed with D1264 (YCp[LYS2]: Ty1), D1242 (YEp[LYS2]), D1251 (YEp[LYS2]: Ty1), D1256 (YEp[LYS2]:pPGK-Ty1 overexpressing Ty1 from the strong PGK1 promoter), and D1257 (YEp[LYS2]:pGALTy1). Transformants from SC-Leu-Lys plates were serial-diluted and spotted onto the indicated solid media and incubated at $30^{\circ} \mathrm{C}$ for 3 d. $5-$ FOA $^{\mathrm{r}} \mathrm{Y} 1144$ D1251 colonies were all tested $\mathrm{Ura}^{+}$.

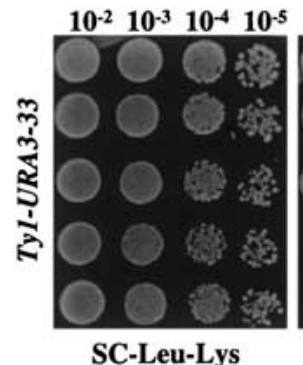

SC-Leu-Lys

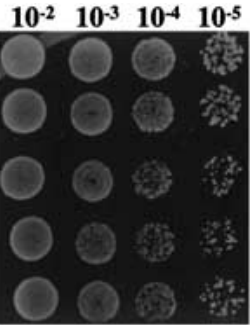

SC-Leu-Lys-Ura

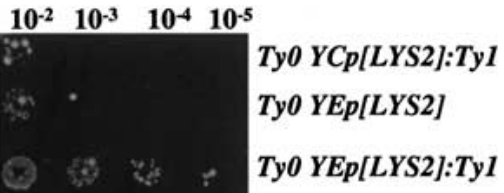

Ty0 YEP[LYS2]:pPGK-Ty1 Ty0 YEp[LYS2]:pGAL-Ty1 determine the role of the native Ty1 promoters in Ty1 cosuppression. Ty1-related genes driven by heterologous promoters were constructed and tested for cosuppression. YEp:pPGK-Ty1 failed to cosuppress Ty1-URA3-33 (Fig. 4), indicating that the native Ty1 promoters are required for Ty1 elements to initiate Ty1 cosuppression. Neither the ORF of Ty1-URA3-33 driven by the MET3 promoter nor URA3-Ty1 gene fusions driven by the URA3 promoter were capable of generating a Ufo phenotype (data not shown), indicating that the native Ty1 promoter is also required for a Ty1-related gene to become a target of Ty1 cosuppression. Although the TyO strain lacks Ty1 and homologous Ty2 elements, it still has many $\delta$ elements (Wilke and Adams 1992), which remain following homologous recombination between the two Ty1 $\delta$ elements (Knight et al. 1996). The fact that cosuppression was not seen in the TyO strain shows that multiple copies of $\delta$ elements are not sufficient to initiate Ty1 cosuppression, and that multiple copies of fulllength Ty1 elements are needed for Ty1 cosuppression. Moreover, YEp:pGAL-Ty1 with no Ty1 transcription (due to the repression of $p G A L$ by glucose in the medium) could not cosuppress Ty1-URA3-33 (Fig. 4), implying that expression of $T y 1$ elements is required for the initiation of Ty1 cosuppression. These experiments point to a key role of the native Ty1 promoters in Ty1 cosuppression.

\section{Digital control of Ty1 transcription and Ty1 TGS}

Because the Ty1 promoters contain cis-acting elements required for $T y 1$ transcriptional regulation, the requirement of the native Ty1 promoters for Ty1 cosuppression implies that Ty1 cosuppression occurs at the level of transcription. If Ty1 cosuppression is transcriptional, changes in Ty1 transcriptional factors should affect Ty 1 cosuppression. Experiments were performed to determine how changes in trans-acting Ty1 transcriptional regulators affect $T y 1$ cosuppression. The diploid-specific transcriptional repressor a1/ $\alpha 2$ lowered the average $T y 1$ mRNA level by a factor of 10 in unsorted cells (a mixture of Ty1-expressing and non-expressing cells; Fig. 3C, cf. lane 2 with lane 1; Elder et al. 1981). The effect of the Ty1 transcriptional repressor a1/ $\alpha 2$ on Ty1 cosuppression was investigated. Y33 with YCp50-LEU2:MATa displayed a colony formation efficiency on SC-Leu + 5FOA 16-fold higher than that of Y33 with YCp50-LEU2 (Table 2, cf. line 2 with line 1). These results show that Ty1 cosuppression occurs much more easily in diploid cells where $T y 1$ elements are transcriptionally repressed. To see if there is a positive correlation between Ty1 transcriptional repression and the 5-FOA ${ }^{\mathrm{r}}$ colony formation efficiency of Ty1-URA3-33 cells, Ty1 cosuppression was examined in $g c n 5$, ste12, and ste11 mutants that lack Ty1 transcriptional activators (Fig. 3C, lanes 5-12). STE12 and STE11 encode components of the invasive/ filamentous growth MAP-kinase pathway that stimulates Ty1 transcription; and GCN5 encodes the catalytic subunit of the SAGA histone acetyltransferase protein complex, a general transcriptional activator. The level of Ty1 mRNA in unsorted isogenic gcn5 5 cells was $5 \%$ of that in unsorted Y33 cells (Fig. 3C, cf. lane 5 with lane 8) and $g c n 5 \Delta$ increased the $5-\mathrm{FOA}^{\mathrm{r}}$ colony formation efficiency of Ty1-URA3-33 cells by a factor of 4.9 (Table 2, cf. line 3 with line 6). Ty1 mRNA levels in unsorted isogenic ste $12 \Delta$ and ste $11 \Delta$ cells were at $9 \%$ and $5 \%$ of that in unsorted Y33 cells, respectively (Fig. 3C, cf. lanes 6 and 7 with lane 8; Dubois et al. 1982). ste12s and

Table 2. 5-FOA $A^{r}$ colony formation efficiencies of Tyl-URA3-33 strains

\begin{tabular}{|c|c|c|c|c|}
\hline & Strain & Genotype & 5-FOA medium & $5 \mathrm{FOA}^{\mathrm{r}}$ colony formation efficiency \\
\hline 1 & Y33 YCp50-LEU2 & $M A T \alpha$ & SC-Leu + 5-FOA & $(2.7 \pm 0.1) \%$ \\
\hline 2 & Y33 YCp50-LEU2:MAT $\boldsymbol{\alpha}$ & $M A T \alpha / \boldsymbol{a}$ & SC-Leu + 5-FOA & $(46 \pm 5) \%$ \\
\hline 3 & Y443 & $M A T \alpha \operatorname{gcn} 5 \Delta$ & $\mathrm{SC}+5-\mathrm{FOA}$ & $(93 \pm 2) \%$ \\
\hline 4 & Y442 & MATa ste $12 \Delta$ & $\mathrm{SC}+5-\mathrm{FOA}$ & $(82 \pm 5) \%$ \\
\hline 5 & Y461 & 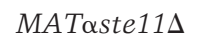 & $\mathrm{SC}+5-\mathrm{FOA}$ & $(92 \pm 1) \%$ \\
\hline 6 & Y33 & $M A T \alpha$ & $\mathrm{SC}+5-\mathrm{FOA}$ & $(16 \pm 3) \%$ \\
\hline
\end{tabular}

5-FOA ${ }^{\mathrm{r}}$ colony formation efficiency was calculated as the number of colonies formed on SC-Leu +5 -FOA (or SC +5 -FOA) divided by the number of colonies formed on SC-Leu (or SC). The presented efficiencies were averaged from three experiments. 
ste11 11 mutations increased the 5-FOA ${ }^{\mathrm{r}}$ colony formation efficiency of Ty1-URA3-33 cells 4.1- and 4.8-fold, respectively (Table 2, cf. lines 4 and 5 with line 6).

The above results indicate that the lowered average Ty1 mRNA levels in unsorted cells of the aforementioned pseudodiploid and haploid mutants are at least partially caused by increased fractions of cells undergoing Ty1 cosuppression. To investigate the possibility that the elevated Ty1 cosuppression frequencies are solely responsible for the lowered Ty1 mRNA levels in the strains, the effects of Ty1 transcriptional regulators on the Ty1 mRNA levels at the cosuppressed state and the coexpressed state were investigated. Ty1 elements in the pseudodiploid cells and the gcn5, ste12, and ste 11 mutants were found completely cosuppressed with Ty1URA3-33 (data not shown), indicating that Ty1 transcriptional regulators do not set the Ty1 mRNA level at the cosuppressed state. This result also rules out the possibility that the increased fractions of $5-\mathrm{FOA}^{\mathrm{r}}$ cells are the result of diminished toxicity of 5-FOA to cells with lower levels of Ty1-URA3-33. The levels of Ty1 mRNA in the Y33 pseudodiploid, Ty1-URA3-33 gcn5 , Ty1URA3-33 ste12s, and Ty1-URA3-33 ste11s haploid cells grown without uracil were found to be $82 \%, 67 \%$, $90 \%$, and $86 \%$ of that in Y33 cells grown without uracil, respectively (Fig. 3C, lanes 3,4,9-12). It is conceivable that actual Ty1 mRNA levels in the pseudodiploid and mutant haploid cells with Ty1 expression are even higher, as it is more difficult to enrich $\mathrm{Ura}^{+}$cells from higher backgrounds of $\mathrm{Ura}^{-}$cells. It was concluded that Ty1 mRNA levels in the pseudodiploid and mutant haploid cells with Ty1 expression were detected at levels experimentally indistinguishable from that in the wildtype haploid. Growth of $U R A^{+}$gcn5 5 , URA $A^{+}$ste11s, $U R A^{+}$ste $12 \Delta$ haploids and $U R A^{+} M A T a / \alpha$ pseudodiploids in media with or without uracil did not result in different Ty1 mRNA levels for each strain (data not shown), ruling out the possibility that the uracil prototrophy selection per se regulates the level of Ty1 mRNA. The same result was obtained with a true Ty1-URA3-33 diploid isogenic strain, Y250 (data not shown). These results indicate that $T y 1$ transcriptional regulators play no role in setting the Ty1 mRNA level at either the cosuppressed state or the coexpressed state. Rather, the elevated Ty1 cosuppression frequencies are solely responsible for the lowered Ty1 mRNA levels in unsorted dip-

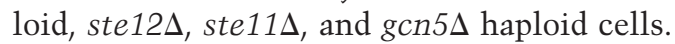

In other words, the transcription of Ty1 elements is under striking digital control with Ty1 transcriptional repressors enhancing Ty1 cosuppression frequency rather than reducing Ty1 transcriptional amplitude in cells expressing Ty1 elements. Digital control of Ty1 transcription contradicts the conventional wisdom that Ty1 transcriptional factors regulate Ty1 transcriptional amplitude and extends the probabilistic enhancer action (enhancers increasing the number of expressing cells rather than the level of gene expression per cell; Walters et al. 1995, 1996; Magis et al. 1996) to dispersed gene repeats.

The observations of a Ty1 transcriptional repressor fa- cilitating the onset of the cosuppressed state and Ty1 transcriptional activators obstructing the onset of the cosuppressed state indicate that turning off Ty1 transcription is a key step in Ty1 cosuppression. Digital control of Ty1 transcription along with the aforementioned requirement of the native Ty1 promoters for Ty1 cosuppression establishes Ty1 cosuppression as TGS.

\section{Calculating the frequency of transient Ty1 cosuppression}

Plating efficiency experiments (Table 1) were performed to determine what fraction of Y33 cells with the Ty1URA3-33 reporter is undergoing cosuppression. These experiments also allowed the calculation of the rate at which a cosuppressed Ty1-URA3-33 reporter comes on (the on-switch rate), and the rate at which an expressed Ty1-URA3-33 reporter is extinguished (the off-switch rate). In these experiments cells from a colony grown on a specific medium (SC, SC-Ura, or SC + 5-FOA) were resuspended in sterile water and plated onto the same medium or a different one. After overnight incubation cells were examined microscopically and plating efficiency was calculated as the fraction of cells that divided at least once on the new plate.

The following two numbers were used to calculate the fraction of Y33 cells with the Ty1-URA3-33 reporter undergoing cosuppression. First, the Ty1 mRNA level of Y33 cells grown in SC-Ura is 2.5-fold higher than when grown in SC (Fig. 3B,C). Second, $11 \%$ of Y33 cells from a colony grown under selection on SC-Ura were able to divide on SC + 5-FOA (Table 1, line 6), indicating that uracil prototrophy selection was only able to enrich Y33 cells with Ty1 expression to a purity of $89 \%$. Together, these results translate to saying that $36 \%(89 \% / 2.5)$ of the Y33 cells grown in SC, without selection, express Ty1-related genes. Thus, the remaining $64 \%$ of Y33 cells grown in SC medium are undergoing Ty1 cosuppression. The fraction of $\mathrm{Y} 33$ cells not expressing Ty1 is surprisingly high.

Data from the plating experiments allowed three independent calculations of the on-switch rate of Ty1URA3-33 in Y33 cells, and similar results were obtained from these calculations. First, the on-switch rate can be calculated by monitoring the fate of $\mathrm{Y} 33$ cells grown on SC + 5-FOA. Only $23 \%$ of Y33 cells from colonies grown under selection on SC + 5-FOA divided on nonselective SC (Table 1, line 7 ), and only $22 \%$ of the Y33 cells grown on SC + 5-FOA divided when plated on the same medium, SC + 5-FOA (Table 1, line 9). These results indicate that cosuppressed Y33 cells, which do not express the Ty1-URA3-33 reporter, frequently lose the cosuppressed state and express Ty1-URA3-33 to cause cell death on 5-FOA. The fact that the live and 5-FOA-resistant cells in Y33 colonies grown on SC +5 -FOA continued to switch allowed a direct calculation of the onswitch rate. Of the plated Y33 cells from colonies grown on SC + 5-FOA, 17\% divided on SC-Ura (Table 1, line 8), and this translates into an on-switch rate of $0.74(17 \% /$ $23 \%)$ per cell generation. 
Second, the on-switch rate can also be calculated by monitoring the actions taken by unsorted Y33 cells after they are plated on SC-Ura. Of the $90 \%$ of Y33 cells grown on SC that divided on SC-Ura (Table 1, line 2), $36 \%$ were cells already expressing Ty1-URA3-33 at the time of plating according to the calculation above. It can be calculated that $54 \%(90 \%-36 \%)$ of the Y33 cells grown nonselectively on SC were cosuppressed at the time of plating but underwent on switches on SC-Ura to express Ty1-URA3-33. This translates into an on-switch rate of $0.84(54 \% / 64 \%)$ per cell generation.

Third, the on-switch rate can also calculated by monitoring the actions taken by the unsorted Y33 cells after they are plated on SC + 5-FOA. Only $22 \%$ of Y33 cells grown nonselectively on SC divided when plated on $\mathrm{SC}+5$-FOA (Table 1, line 3), indicating that only $34 \%$ $(22 \% / 64 \%)$ of the originally cosuppressed cells remained cosuppressed for one cell generation. This calculates to an on-switch rate of $0.66(1-0.34)$ per cell generation.

Microscopic examination of Y33 cells plated on $\mathrm{SC}+5$-FOA showed both colonies and microcolonies (Fig. 2A, right). The existence of these microcolonies indicates that Ty1-URA3-33 was not expressed in the founding cell of a microcolony, allowing division on 5-FOA, but that rapid on switches sometimes caused all progeny of a cosuppressed cell to be killed by 5-FOA. This also provides an explanation for the Y33 5FOA ${ }^{\mathrm{r}}$ colony formation efficiency $(16 \%)$ being lower than the microscopic 5-FOA-plating efficiency (22\%).

It was difficult if not impossible to determine the rate of off switches. Although the plating efficiency of Y33 cells grown on SC-Ura and then replated on the same medium was determined (Table 1, line 5), this value could not be used to directly measure the off-switch rate. Among these cells, those that underwent off switches after being replated onto SC-Ura were tolerated because they could undergo the aforementioned rapid on switches and eventually divide on SC-Ura. Because coexpressed Y33 cells that express Ty1-URA3-33 can not survive long enough to undergo off switches on $\mathrm{SC}+5$ FOA, the microscopic 5-FOA-plating efficiency of Y33 cells from SC-Ura (Table 1, line 6) does not reflect the fraction of coexpressed cells undergoing off switches on SC + 5-FOA. Nonetheless, an estimate for the off-switch rate can be made as follows. Assuming that Y33 cells grown in SC are at equilibrium with $64 \%$ cosuppressed cells and $36 \%$ coexpressed cells, the number of cosuppressed cells undergoing on switches $(64 \% \times 0.74$ per cell generation) should equal the number of Ty1-expressing cells undergoing off switches $(36 \% \times$ the off-switch rate). This allows an estimation of the off-switch rate to be 1.3 per cell generation. In summary, both the on-switch and off-switch rates are extremely high, consistent with the idea that Ty1 cosuppression lacks mitotic stability.

\section{Discussion}

Ty1 transcriptional cosuppression is documented in this report as a novel cosuppression. On one hand, it has the key characteristics of classical TGS in plants: induction by high gene copy number, homology-dependence, and a possible function of molecular parasite control (see below). On the other hand, Ty1 cosuppression displays unique features. TGS in plants is usually mitotically stable, whereas Ty1 cosuppression is transient. TGS in plants is usually associated with DNA methylation. Because there is no DNA methylation in S. cerevisiae, Ty1 cosuppression is the first clear example of DNA-methylation-independent TGS. Multicopy promoter sequences are sufficient to induce TGS in plants (Vaucheret and Fagard 2001), but multicopy $\delta$ elements fail to initiate Ty1 cosuppression (Fig. 4).

\section{Cosuppression-mediated negative feedback control of Tyl transcription}

The initiation of Ty1 cosuppression by high Ty1 copy number suggests the existence of a negative feedback control mechanism regulating Ty1 transcription. The high switch rates of Ty1 cosuppression point to a dynamic pattern of Ty1 transcription in vivo. Ty1 transcription in a wild-type haploid is blocked by cosuppression at such a high frequency (1.3 per cell generation) that Ty1 elements are mostly cosuppressed (for $64 \%$ of a cell cycle). This pattern of Ty1 transcription is consistent with the idea of cosuppression mediating negative feedback control of Ty1 expression. It is possible that a yet to be identified Ty1 gene product inhibits Ty1 transcription and acts to initiate Ty1 cosuppression. The production of this putative Ty1 gene product is expected to depend on the structure or function of the native $T y 1$ promoter, as $p P G K-T y 1$ and $P G A L-T y 1$ failed to initiate Ty1 cosuppression (Fig. 4). Ty1 reverse transcriptase is inhibited by $0.2 \mathrm{mg} / \mathrm{mL}$ phosphonoformic acid (PFA; Lee et al. 2000). However, this concentration of PFA does not affect Ty1 cosuppression in Y33 cells (data not shown), showing that Ty1 cDNA does not function as the feedback signaling molecule. Experiments are in progress to determine what minimal Ty1 sequences are required to initiate cosuppression in a TyO strain, and this may shed light on the Ty1 gene product that initiates Ty1 cosuppression.

\section{Cosuppression and Tyl transposition}

Because Ty1 transposition can be mutagenic, there must be selective pressure to evolve mechanisms regulating Ty1 transposition. Ty1 transposition is largely limited to noncoding regions of the genome (Devine and Boeke 1996). However, such target restriction is not $100 \%$ effective, and Ty1 transpositions into coding regions do occur (Natsoulis et al. 1989). Therefore, there is selective pressure for mechanisms to reduce the activities leading to Ty1 transposition. Indeed, Ty1 elements in wild-type cells are dormant under normal growth conditions. The dormancy involves specific host genes, and mutations in FUS3, RAD52, CDC9, SSL2, and RAD3 cause Ty1 hypertransposition (Conte et al. 1998; Lee et al. 1998, 2000; Conte and Curcio 2000; Rattray et al. 2000). Ty1 trans- 
position is induced by stressful conditions such as nitrogen starvation through the activation of the invasive/ filamentous growth pathway (Morillon et al. 2000) or DNA damage through the activation of the Rad9-mediated DNA-damage-response pathway (Bradshaw and McEntee 1989; Staleva and Venkov 2001). Ty1 elements may bring their host the benefit of adaptive mutagenesis (Morillon et al. 2000) to improve the fitness of the host (Wilke and Adams 1992; Knight et al. 1996). Moreover, Ty1 elements can play a role in DNA repair (an extreme form of adaptive mutagenesis), as Ty1 cDNA fragments have been found in repair patches following doublestranded DNA breaks (Moore and Haber 1996; Teng et al. 1996; Yu and Gabriel 1999). Ty1 cosuppression seems to play an important role in suppressing Ty1 hypertransposition. Preliminary experiments show abolished Ty1 transcriptional cosuppression associated with all the known mutations and environmental conditions that cause Ty1 hypertransposition (Y.W. Jiang, unpubl.).

\section{Chromatin-remodeling and \\ DNA-methylation-independent TGS}

It is commonly assumed that transcription of repetitive genes in euchromatic regions is automatically coregulated. However, our previous studies have shown that transcriptional coregulation of two solo $\delta$ elements in a cell is not a given, and that it involves chromatin remodeling. ACT3/ARP4 encodes a subunit of two chromatinremodeling protein complexes, the NuA4 histone acetyltransferase complex (Galarneau et al. 2000) and the Ino80 ATP-dependent chromatin-remodeling complex (Shen et al. 2000). We reported that a recessive allele of ACT3/ARP4 (act3-3) caused mosaic expression of two $\delta$ elements in the same cell (Jiang and Stillman 1996). It will be interesting to see whether chromatin remodeling plays a role in the transcriptional coregulation of the $\delta$ elements in Ty1 cosuppression.

DNA methylation had been regarded as the most important aspect of chromatin remodeling in TGS of plants; however, it was recently reported that mutations of an Arabidopsis gene, MOM, reactivated transcription from heavily methylated and previously silenced loci, separating transcriptional activity from methylation pattern (Amedeo et al. 2000). The predicted MOM gene product is a nuclear protein of 2001 amino acids containing a region similar to the ATPase region of the chromatin-remodeling Swi2/Snf2 family, and it is suggested that MOM acts downstream of DNA methylation. Further work is needed to determine whether any chromatinremodeling activity is required for Ty1 cosuppression, which must be independent of DNA methylation because there is no DNA methylation in $S$. cerevisiae.

\section{Materials and methods}

YEPD, SC, SC-Ura, and SC + 5-FOA media preparation, cloning, yeast transformation, and Northern procedures were performed as previously described (Jiang and Stillman 1996). The preparation of SC + FAA (Toyn et al. 2000) and PCR-mediated site- directed mutagenesis (Howorka and Bayley 1998) were performed according to published protocols.

\section{Plasmids}

A BamHI-KpnI linker $\left(5^{\prime}>\right.$ ggatccgtcgagggggggcceggtacc $\left.>3^{\prime}\right)$ and URA3OT as a 900-bp KpnI-HindIII fragment from pPSG-B (Silar and Thiele 1991) were ligated into the BamHI/HindIII sites of an EcoRI-less m-Tn3 (Seifert et al. 1986) to create D467. The HindIII site in D467 was destroyed to create D468 pTn3URA3OT. The 11-kb EcoRI fragment of D547 containing Ty1-URA3-33 was cloned into the EcoRI site of a YCplac111[LEU2] vector to create D804. The 6-kb XbaI-EcoRI fragment of D547 containing Ty1-URA3-33 was cloned into a YCplac111[LEU2] vector to create D806. The 600-bp BamHIStuI fragment of pJJ242 was ligated with the 11-kb BamHI-StuI fragment of D806 to create D1261 \{YCp[LEU2]:ty1::URA3(A)\} with wild-type $U R A 3$ (driven by its own promoter) inserted at nucleotide 902 of Ty1 in the same orientation. The $1.2-\mathrm{kb}$ BamHI-AatII fragment of $p$ Tn3:URA3 was ligated with the 11-kb BamHI-AatII fragment of D806 to create D1262 $\{Y C p[L E U 2]: t y 1:: U R A 3(B)\}$ with wild-type URA3 (driven by its own promoter) inserted at nucleotide 902 of Ty1 in the opposite orientation. The 3.8-kb BamHI-BglII fragment of pNKY51 (Alani et al. 1987) containing a URA3 popout was cloned into the BamHI site of pTn3 to create D611 pTn3:URA3 (popout). The genomic DNA of yeast strain 337 was digested with HindIII to completion and ligated into the HindIII site of pHSS6 to create a genomic library of 337 . The genomic library was transformed into the leu6B E. coli strain $\mathrm{KC} 8$ for $\mathrm{Leu}^{+}$transformants from which D623 contains LEU2 from strain 337 was isolated. D623 was mutagenized with Tn3:URA3 popout carried by D611 to create an leu2::URA3 (popout) library D672. The 8-kb NotI fragment of D572 containing Ty1 was cloned into the NotI site of pRS317 to create D1264 (YCp[LYS2]Ty1). The $2 \mu$ plasmid as an HpaI fragment was cloned into the SmaI site of YDp-K to create D766. The SalI site in D766 was converted into an NotI site to create D772. The super polylinker of pSL1180 as an HindIIIEcoRI fragment was cloned into the HindIII/EcoRI sites of pHSS6 to create D825 (pHSS6 with Superlinker). The SmaI fragment of D825 was deleted to create D1241. The 2.3-kb NotI-AatII fragment of D772 containing the pUC backbone was replaced with D1241 as a 2.2-kb NotI-AatII fragment to create D1242 (YEp[LYS2]). The 8-kb NotI fragment of D572 containing Ty1 was cloned into the NotI site of D1242 to create D1251 (YEp[LYS2]:Ty1). The 1.5-kb HindIII-XhoI fragment of pI2L2 (YEp:pPGK-L-A[TRP1]; Wickner et al. 1991) containing pPGK1 was cloned into the HindIII/XhoI sites of M1498 (YEplac181[LEU2] with BSKSII) to create D745 (YEp[LEU2]). The Ty1 coding region plus $3^{\prime}-\delta$ as an XhoI-ApaI fragment from D570 (YEp[LEU2]:Ty1) was cloned into the XhoI/ApaI sites of D745 to create D848 (YEp[LEU2]:pPGK-Ty1). D848 was digested with $A p a \mathrm{I}$ and ligated to an ApaI to NotI converter $\left(5^{\prime}>\right.$ gcggecgeggec $\left.>3^{\prime}\right)$ to create D1253. The 8-kb NotI fragment of D1253 containing Ty1 was cloned into the NotI site of D1242 to create D1256 (YEp[LYS2]:pPGK-Ty1). D571 (YEp[LEU2]:pGAL-Ty1) was digested with ApaI and ligated to an ApaI to NotI converter $\left(5^{\prime}>\operatorname{gcggccgcggcc}>3^{\prime}\right)$ to create D1255. The 8-kb NotI fragment of D1255 containing Ty1 was cloned into the NotI site of D1242 to create D1257 (YEp[LYS2]:pGAL-Ty1). The 4.5-kb KpnI-SacI fragment of D871 containing STE11 was cloned into the $\mathrm{KpnI} / \mathrm{SacI}$ sites of BS $\mathrm{KS}^{+}$ to create D872. The 2-kb EcoRI-PstI fragment of D872 containing the STE11 ORF was replaced by the 700-bp EcoRI-PstI fragment of pJJ248 containing TRP1 to create D873 (ste11::TRP1 in BS). 
Table 3. Yeast strains

\begin{tabular}{|c|c|c|c|}
\hline Strain & Genotype & Background & Source \\
\hline W303A & 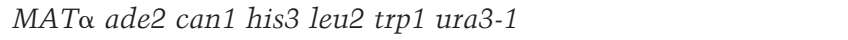 & W303 & R. Rothstein \\
\hline W303B & MAT $\boldsymbol{\alpha}$ ade2 can1 his3 leu2 trp1 ura3-1 & W303 & R. Rothstein \\
\hline DY4073 & MAT $\alpha$ ade2 can1 his3 leu2 lys2 trp1 & W303 & D.J. Stillman \\
\hline Y32 & MAT $\alpha$ Ty1-URA3-32 ade2 can1 his3 leu2 trp1 ura3-1 & W303 & This study \\
\hline Y33 & MAT $\alpha$ Ty1-URA3-33 ade2 can1 his3 leu2 trp1 ura3-1 & W303 & This study \\
\hline Y1149 & MAT $\alpha$ ade2 can1 his3 leu2 ura3 & W303 & This study \\
\hline Y1203 & MAT/ $T y 1-T R P 1 K L$ ade2 can1 his3 leu2 ura3 & W303 & This study \\
\hline UCC16 & MAT $\boldsymbol{\alpha}$ adh4::URA3 ade2 can1 his3 leu2 trp1 ura3 & W303 & D. Gottschling \\
\hline Y442 & MATa Tyl-URA3-33 ste12::Leu2 ade2 can1 his3 leu2 trp1 ura3 & W303 & This study \\
\hline Y461 & 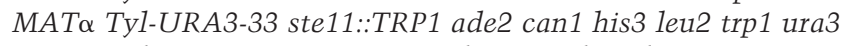 & W303 & This study \\
\hline Y443 & MATa Tyl-URA3-33 gcn5::HIS3 ade2 can1 his3 leu2 trp1 ura3 & W303 & This study \\
\hline YPH499 & MATa ade2 gal3 his3 leu2 lys2 trp1s1 ura3-52 & S288C & P. Heiter \\
\hline 337 & MAT $\alpha$ TyO gal3 ura3 $\rho^{-}$ & 337 & C.M. Wilke \\
\hline Y200 & MAT $\alpha$ Ty0 gal3 lys2 ura3 $\rho^{-}$ & 337 & This study \\
\hline Y211 & 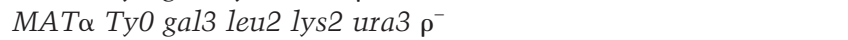 & 337 & This study \\
\hline Y1140 & MATa Ty0 gal3 leu2 lys2 ura3 & 337 & This study \\
\hline Y1144 & MATa Ty0 gal3 leu2 lys2 ura3 YCp [LEU2]Ty1-URA3-33 & 337 & This study \\
\hline
\end{tabular}

\section{Strain constructions}

The strains used in this study are listed in Table 3. The coding region of the Kluyveromyces lactis TRP1 gene was PCRamplified from pBS1479 with primers D1238 $\left(5^{\prime}>\right.$ ACAT CAAATTTTTACAAAACTCGAATCTCGGTGGTATTATTC tgctcgttaaagtgtgtggtttg $\left.>3^{\prime}\right)$ and D1239 $\left(5^{\prime}>\right.$ TGAGTTCAT CATCAGTGATCTGACGTACGGGTTTTCCGTTTACTG TCGtcgaattcctgcagccc $>3^{\prime}$ ) to create a Ty1-TRP1KL in-frame gene fusion knock-in construct (with the junction at nucleotide 902 of Ty1). Y1150 was a $\operatorname{Trp}^{+}$transformant of a W303 strain with the Ty1-TRP1KL knock-in construct DNA, and recombination between the knock-in construct and a single Ty1 element was verified by Southern (with a Ty1-TRP1KL probe) and successful cloning of a full-length Ty1-TRP1KL. Y1150 was backcrossed once to obtain Y1203. Y442 was a $\mathrm{Leu}^{+}$sterile transformant of Y33 transformed with pSUL16 ste12::LEU2 gene disrupter (Fields and Herskowitz 1987) digested with SacI and SphI. A W303 gcn5::HIS3 strain DY5925 (a gift from D.J. Stillman, University of Utah, Salt Lake City) was crossed with Y33 to create Y443. Y461 was a Trp ${ }^{+}$sterile transformant of Y33 transformed with a D873 ste11::TRP1 gene disrupter digested with SacI and KpnI. P. Philippsen and M. Ciriarcy created TyO strain 337 by deleting the only Ty1 element from a wild isolate (Wilke and Adams 1992). Y200 was an $\alpha$-aminoadipate-resistant lys2 mutant of TyO strain 337 . Y200 was transformed with the leu2::URA3 (popout) library D672 linearized with NotI for $\mathrm{Ura}^{+} \mathrm{Leu}^{-}$transformants from which a 5-FOA-resistant strain (Y211) was then obtained. The $\rho$ defect of Y211 was corrected by cytoduction (Lancashire and Mattoon 1979) with a kar1-1 mutant MY686 (a gift from C.M. Rose, Princeton University, New Jersey) to obtain $\rho+\alpha$-aminoadipate-resistant Y1140, whose Ty0 status was verified by a Southern with a $2.3-\mathrm{kb}$ SalI-EcoRI Ty1 probe that recognizes both the Ty1 and Ty2 ORFs. Y1140 was transformed with D804 to generate Y1144.

\section{Acknowledgments}

This work was supported initially by a DRWW Postdoctoral Fellowship awarded to Y.W.J. and later by faculty start-up funds and the Tobacco Endowment Fund from Texas A\&M University System Health Science Center School of Medicine. The author is a Lallage Feazel Wall Scholar, and the work is partially supported by the Cancer Research Fund of the Damon RunyonWalter Winchell Foundation Award, DRS-23. The author thanks Roger Kornberg for encouragement and support and G. Kapler, W. Voth, T. Formosa, J. Boeke, R. Rothstein, D. Gottschling, M. Rose, and C.M. Wilke for comments, suggestions, or reagents. The author is extremely grateful for the intellectual and editorial contributions from D.J. Stillman and the Genes \& Development reviewer in finalizing the manuscript.

The publication costs of this article were defrayed in part by payment of page charges. This article must therefore be hereby marked "advertisement" in accordance with 18 USC section 1734 solely to indicate this fact.

\section{References}

Alani, E., Cao, L., and Kleckner, N. 1987. A method for gene disruption that allows repeated use of URA3 selection in the construction of multiply disrupted yeast strains. Genetics 116: 541-545.

Al-Kaff, N.S., Covey, S.N., Kreike, M.M., Page, A.M., Pinder, R., and Dale, P.J. 1998. Transcriptional and posttranscriptional plant gene silencing in response to a pathogen. Science 279: 2113-2115.

Amedeo, P., Habu, Y., Afsar, K., Scheid, O.M., and Paszkowski, J. 2000. Disruption of the plant gene MOM releases transcriptional silencing of methylated genes. Nature 405: 203206.

Assaad, F.F., Tucker, K.L., and Signer, E.R. 1993. Epigenetic repeat-induced gene silencing (RIGS) in Arabidopsis. Plant Mol. Biol. 22: 1067-1085.

Bass, B.L. 2000. Double-stranded RNA as a template for gene silencing. Cell 101: 235-238.

Baur, M., Esch, R.K., and Errede, B. 1997. Cooperative binding interactions required for function of the Tyl sterile responsive element. Mol. Cell. Biol. 17: 4330-4337.

Belcourt, M.F. and Farabaugh, P.J. 1990. Ribosomal frameshifting in the yeast retrotransposon Ty: tRNAs induce slippage on a 7 nucleotide minimal site. Cell 62: 339-352.

Boeke, J.D., Trueheart, J., Natsoulis, G., and Fink, G.R. 1987. 5-Fluoroorotic acid as a selective agent in yeast molecular genetics. Meth. Enzymol. 154: 164-175.

Bradshaw, V.A. and McEntee, K. 1989. DNA damage activates 
transcription and transposition of yeast Ty retrotransposons. Mol. Gen. Genet. 218: 465-474.

Burns, N., Grimwade, B., Ross-Macdonald, P.B., Choi, E.Y., Finberg, K., Roeder, G.S., and Snyder, M. 1994. Large-scale analysis of gene expression, protein localization, and gene disruption in Saccharomyces cerevisiae. Genes \& Dev. 8: 1087-1105.

Chapman, K.B., Bystrom, A.S., and Boeke, J.D. 1992. Initiator methionine tRNA is essential for Ty1 transposition in yeast. Proc. Nat1. Acad. Sci. 89: 3236-3240.

Company, M., Adler, C., and Errede, B. 1988. Identification of a Ty1 regulatory sequence responsive to STE7 and STE12. Mol. Cell. Biol. 8: 2545-2554.

Conte, D. and Curcio, M.J. 2000. Fus3 controls Ty1 transpositional dormancy through the invasive growth MAPK pathway. Mol. Microbiol. 35: 415-427.

Conte, D.J., Barber, E., Banerjee, M., Garfinkel, D., and Curcio, M. 1998. Posttranslational regulation of Ty1 retrotransposition by mitogen-activated protein kinase Fus3. Mol. Cell. Biol. 18: 2502-2513.

Denis-Duphil, M. 1989. Pyrimidine biosynthesis in Saccharomyces cerevisiae: The ura2 cluster gene, its multifunctional enzyme product, and other structural or regulatory genes involved in de novo UMP synthesis. Biochem. Cell. Biol. 67: 612-631.

Devine, S.E. and Boeke, J.D. 1996. Integration of the yeast retrotransposon Tyl is targeted to regions upstream of genes transcribed by RNA polymerase III. Genes \& Dev. 10: 620 633.

Dubois, E., Jacobs, E., and Jauniaux, J.C. 1982. Expression of the ROAM mutations in Saccharomyces cerevisiae: Involvement of trans-acting regulatory elements and relation with the Ty1 transcription. EMBO J. 1: 1133-1139.

Eichinger, D.J. and Boeke, J.D. 1988. The DNA intermediate in yeast Tyl element transposition copurifies with virus-like particles: Cell-free Ty1 transposition. Cell 54: 955-966.

Elder, R.T., St John, T.P., Stinchcomb, D.T., Davis, R.W., and Scherer, S. 1981. Studies on the transposable element Ty1 of yeast. I. RNA homologous to Ty1. II. Recombination and expression of Ty1 and adjacent sequences. Cold Spring Harb. Symp. Quant. Biol. 45: 581-591.

Errede, B., Company, M., and Hutchison, C.A., III. 1987. Ty1 sequence with enhancer and mating-type-dependent regulatory activities. Mol. Cell. Biol. 7: 258-265.

Fields, S. and Herskowitz, I. 1987. Regulation by the yeast mating-type locus of STE12, a gene required for cell-type-specific expression. Mol. Cell. Biol. 7: 3818-3821.

Galarneau, L., Nourani, A., Boudreault, A.A., Zhang, Y., Heliot, L., Allard, S., Savard, J., Lane, W.S., Stillman, D.J., and Cote, J. 2000. Multiple links between the NuA4 histone acetyltransferase complex and epigenetic control of transcription. Mol. Cell 5: 927-937.

Gottschling, D.E., Aparicio, O.M., Billington, B.L., and Zakian, V.A. 1990. Position effect at $S$. cerevisiae telomeres: Reversible repression of Pol II transcription. Cell 63: 751-762.

Grant, S.R. 1999. Dissecting the mechanisms of posttranscriptional gene silencing: Divide and conquer. Cell 96: 303-306.

Hamilton, A.J. and Baulcombe, D.C. 1999. A species of small antisense RNA in posttranscriptional gene silencing in plants. Science 286: 950-952.

Hammond, S.M., Bernstein, E., Beach, D., and Hannon, G.J. 2000. An RNA-directed nuclease mediates post-transcriptional gene silencing in Drosophila cells. Nature 404: 293 296.

Howorka, S. and Bayley, H. 1998. Improved protocol for highthroughput cysteine scanning mutagenesis. Biotechniques
25: $764-770$

Ingelbrecht, I., Van Houdt, H., Van Montagu, M., and Depicker, A. 1994. Posttranscriptional silencing of reporter transgenes in tobacco correlates with DNA methylation. Proc. Natl. Acad. Sci. 91: 10502-10506.

Jiang, Y.W. and Stillman, D.J. 1996. Epigenetic effects on yeast transcription caused by mutations in an actin-related protein present in the nucleus. Genes \& Dev. 10: 604-619.

Jones, L., Hamilton, A.J., Voinnet, O., Thomas, C.L., Maule, A.J., and Baulcombe, D.C. 1999. RNA-DNA interactions and DNA methylation in post-transcriptional gene silencing. Plant Cell 11: 2291-2302.

Jorgensen, R.A. 1995. Cosuppression, flower color patterns, and metastable gene expression states. Science 268: 686-691.

Knight, S.A., Labbe, S., Kwon, L.F., Kosman, D.J., and Thiele, D.J. 1996. A widespread transposable element masks expression of a yeast copper transport gene. Genes \& Dev. 10: 1917-1929.

Laloux, I., Dubois, E., Dewerchin, M., and Jacobs, E. 1990. TEC1, a gene involved in the activation of Tyl and Ty1mediated gene expression in Saccharomyces cerevisiae: Cloning and molecular analysis. Mol. Cell. Biol. 10: 35413550.

Lancashire, W.E. and Mattoon, J.R. 1979. Cytoduction: A tool for mitochondrial genetic studies in yeast. Utilization of the nuclear-fusion mutation kar 1-1 for transfer of drug $\mathrm{r}$ and mit genomes in Saccharomyces cerevisiae. Mol. Gen. Genet. 170: 333-344.

Lee, B., Lichtenstein, C., Faiola, B., Rinckel, L., Wysock, W., Curcio, M., and Garfinkel, D. 1998. Posttranslational inhibition of Ty1 retrotransposition by nucleotide excision repair/transcription factor TFIIH subunits Ssl2p and Rad3p. Genetics 148: 1743-1761.

Lee, B.S., Bi, L., Garfinkel, D.J., and Bailis, A.M. 2000. Nucleotide excision repair/TFIIH helicases RAD3 and SSL2 inhibit short-sequence recombination and Tyl retrotransposition by similar mechanisms. Mol. Cell. Biol. 20: 2436-2445.

Madhani, H.D. and Fink, G.R. 1997. Combinatorial control required for the specificity of yeast MAPK signaling. Science 275: 1314-1317.

Magis, W., Fiering, S., Groudine, M., and Martin, D.I. 1996. An upstream activator of transcription coordinately increases the level and epigenetic stability of gene expression. Proc. Natl. Acad. Sci. 93: 13914-13918.

Merkulov, G.V., Swiderek, K.M., Brachmann, C.B., and Boeke, J.D. 1996. A critical proteolytic cleavage site near the $\mathrm{C}$ terminus of the yeast retrotransposon Tyl Gag protein. J. Virol. 70: 5548-5556.

Merkulov, G.V., Lawler, Jr., J.F., Eby, Y., and Boeke, J.D. 2001. Ty1 proteolytic cleavage sites are required for transposition: All sites are not created equal. J. Virol. 75: 638-644.

Mette, M.F., Aufsatz, W., van der Winden, J., Matzke, M.A., and Matzke, A.J. 2000. Transcriptional silencing and promoter methylation triggered by double- stranded RNA. EMBO $I$. 19: 5194-5201.

Moore, J.K. and Haber, J.E. 1996. Capture of retrotransposon DNA at the sites of chromosomal double-strand breaks. $\mathrm{Na}$ ture 383: 644-646.

Morillon, A., Springer, M., and Lesage, P. 2000. Activation of the Kss 1 invasive-filamentous growth pathway induces Ty1 transcription and retrotransposition in Saccharomyces cerevisiae. Mol. Cell. Biol. 20: 5766-5776.

Natsoulis, G., Thomas, W., Roghmann, M.C., Winston, F., and Boeke, J.D. 1989. Ty1 transposition in Saccharomyces cerevisiae is nonrandom. Genetics 123: 269-279.

Pal-Bhadra, M., Bhadra, U., and Birchler, J. 1997. Cosuppression 
in Drosophila: Gene silencing of alcohol dehydrogenase by white-Adh transgenes is Polycomb dependent. Cell 90: 479490.

Rattray, A.J., Shafer, B.K., and Garfinkel, D.J. 2000. The Saccharomyces cerevisiae DNA recombination and repair functions of the RAD52 epistasis group inhibit Ty1 transposition. Genetics 154: 543-556.

Rolfe, M., Spanos, A., and Banks, G. 1986. Induction of yeast Ty element transcription by ultraviolet light. Nature 319: 339340.

Rossignol, J.L. and Faugeron, G. 1994. Gene inactivation triggered by recognition between DNA repeats. Experientia 50: $307-317$.

Seifert, H.S., Chen, E.Y., So, M., and Heffron, F. 1986. Shuttle mutagenesis: A method of transposon mutagenesis for Saccharomyces cerevisiae. Proc. Natl. Acad. Sci. 83: 735-739.

Shen, X., Mizuguchi, G., Hamiche, A., and Wu, C. 2000. A chromatin remodelling complex involved in transcription and DNA processing. Nature 406: 541-544.

Silar, P. and Thiele, D.J. 1991. New shuttle vectors for direct cloning in Saccharomyces cerevisiae. Gene 104: 99-102.

Staleva, L. and Venkov, P. 2001. Activation of Ty transposition by mutagens. Mutat. Res. 474: 93-103.

Teng, S.C., Kim, B., and Gabriel, A. 1996. Retrotransposon reverse-transcriptase-mediated repair of chromosomal breaks. Nature 383: 641-644.

Toyn, J.H., Gunyuzlu, P.L., White, W.H., Thompson, L.A., and Hollis, G.F. 2000. A counterselection for the tryptophan pathway in yeast: 5 -Fluoroanthranilic acid resistance. Yeast 16: $553-560$.

Vaucheret, H. and Fagard, M. 2001. Transcriptional gene silencing in plants: Targets, inducers and regulators. Trends Genet. 17: 29-35.

Walters, M.C., Fiering, S., Eidemiller, J., Magis, W., Groudine, M., and Martin, D.I. 1995. Enhancers increase the probability but not the level of gene expression. Proc. Natl. Acad. Sci. 92: 7125-7129.

Walters, M.C., Magis, W., Fiering, S., Eidemiller, J., Scalzo, D., Groudine, M., and Martin, D.I. 1996. Transcriptional enhancers act in cis to suppress position-effect variegation. Genes \& Dev. 10: 185-195.

Wassenegger, M., Heimes, S., Riedel, L., and Sanger, H.L. 1994. RNA-directed de novo methylation of genomic sequences in plants. Cell 76: 567-576.

Wickner, R.B., Icho, T., Fujimura, T., and Widner, W.R. 1991. Expression of yeast L-A double-stranded RNA virus proteins produces derepressed replication: A ski- phenocopy. J. Virol. 65: $155-161$

Wilke, C. and Adams, J. 1992. Fitness effects of Ty transposition in Saccharomyces cerevisiae. Genetics 131: 31-42.

Wolffe, A.P. and Matzke, M.A. 1999. Epigenetics: Regulation through repression. Science 286: 481-486.

Youngren, S.D., Boeke, J.D., Sanders, N.J., and Garfinkel, D.J. 1988. Functional organization of the retrotransposon Ty from Saccharomyces cerevisiae: Ty protease is required for transposition. Mol. Cell. Biol. 8: 1421-1431.

$\mathrm{Yu}, \mathrm{X}$. and Gabriel, A. 1999. Patching broken chromosomes with extranuclear cellular DNA. Mol. Cell 4: 873-881.

Zamore, P.D., Tuschl, T., Sharp, P.A., and Bartel, D.P. 2000. RNAi: Double-stranded RNA directs the ATP-dependent cleavage of mRNA at 21 to 23 nucleotide intervals. Cell 101: $25-33$ 


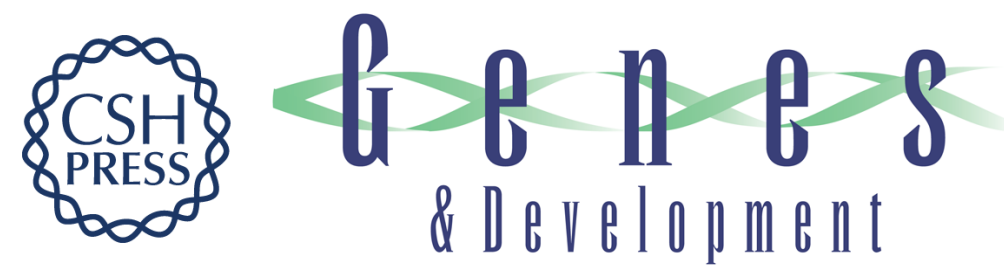

\section{Transcriptional cosuppression of yeast Ty1 retrotransposons}

Yi Wei Jiang

Genes Dev. 2002, 16:

Access the most recent version at doi:10.1101/gad.923502

References This article cites 63 articles, 34 of which can be accessed free at: http://genesdev.cshlp.org/content/16/4/467.full.html\#ref-list-1

License

Email Alerting Receive free email alerts when new articles cite this article - sign up in the box at the top Service right corner of the article or click here.

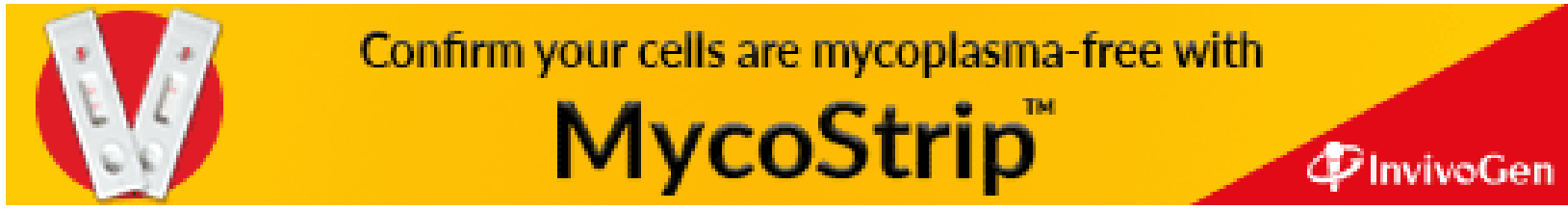

